\title{
On the impact of the COVID-19 pandemic on alpine research projects in Montana
}

\author{
Martha E. Apple \\ Keywords: alpine, plant, ecology, Montana, pandemic
}

\section{Abstract}

Alpine field research often involves travel and hiking to steep but gorgeous mountain ranges where days are spent outdoors, and in our case, in botanical/ecological/sensor research. Under the usual conditions, alpine field researchers in Montana need to consider integral hazards such as cliffs, snow, stormy weather, the alpine sun, and bears. But what influence does a pandemic have on alpine field research?

\section{Introduction}

Severe acute respiratory syndrome coronavirus 2 (SARS-CoV-2) causes COVID-19 disease (Chen et al. 2020), which is now a pandemic that has caused the deaths of over one million people (Dong et al. 2020). Although Montana is relatively isolated, COVID-19 is still here and it is spreading rapidly, with 715 new cases reported on 9 October 2020 (Montana Dept. of Health and Human Services and Montana State Library 2020). Because there is no vaccination against COVID-19, and because it is an easily transmitted and potentially deadly virus, humans protect themselves and others by quarantines, social distancing, mask-wearing, and hand washing (Center for Disease Control 2020). Because of this very serious situation, ongoing changes have been made in the ways that humans conduct their activities. Still, politics influence whether people follow COVID-19 precautions and a dichotomy exists between people who wear masks and those who vocally oppose mask-wearing. Although on 15 July 2020 Montana Governor Steve Bullock issued a mandate for mask-wearing in Montana (Bullock 2020), people opposing the mandate have staged protests. It somewhat resembles the 1854 London cholera epidemic, when, in one of the world's first formal epidemiological studies, John Snow traced the epidemic's source to water from the Broad St. well. After his life-saving discovery the pump handle was removed, but authorities put the pump handle back on! (Brody et al. 2000).

A vast array of gatherings and events have been cancelled, postponed, or changed due to the COVID-19 pandemic. One example is that the Montana University System's fall semester started early, on 17 August, and will end in mid-November, with the idea that the early finish may reduce travel-related COVID-19 spread during the high-travel months of November and December. But this effectively reduces the number of available field days for professors.

Here I recount our summer 2020 alpine field research in light of the COVID-19 pandemic at the Montana field sites in the Anaconda-Pintler Wilderness, the Pioneer Mountains, the Highland Mountains, and at Glacier National Park.

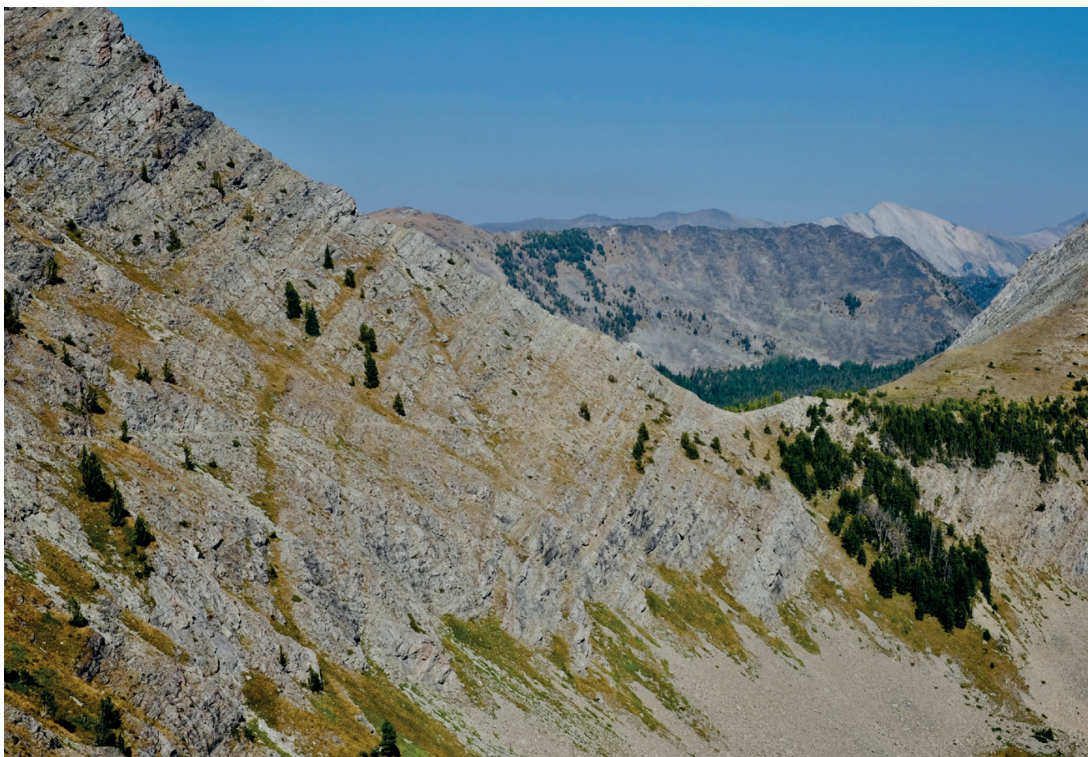

Figure 1 - The trail from Goat Flat looking towards Storm Pass, 6 September 2020.

\section{Montana field sites}

\section{Anaconda-Pintler Wilderness}

Goat Flat, $\left(2837 \mathrm{~m} ; 46.3017^{\circ} \mathrm{N}, 113.1643^{\circ} \mathrm{W}\right)$, is a plateau of alpine tundra in the Pintler Mts. of the Anaconda-Pintler Wilderness in southwestern Montana. It has late-lying snowfields, solifluction lobes, and periglacial-patterned ground where we study plant functional traits and species distribution (Apple et al. 2019). Because Goat Flat is virtually inaccessible most of the year due to heavy snows and a steeply angled cirque, we are developing sensors and sensor networks to transmit soil moisture and temperature data remotely.

The trail to Goat Flat is $5.6 \mathrm{~km}$ long with an elevation gain of $296 \mathrm{~m}$ from the trailhead at Storm Lake to the periglacial patterned ground. While this trail is most sublime while walking past Storm Lake, through a forest, and ascending switchbacks to Storm Pass, the trail then cuts into the rock wall of a glacial cirque to make the dramatic crossing to Goat Flat (Figure 1). Along the glacial cirque the cliff rises sharply to the hiker's 


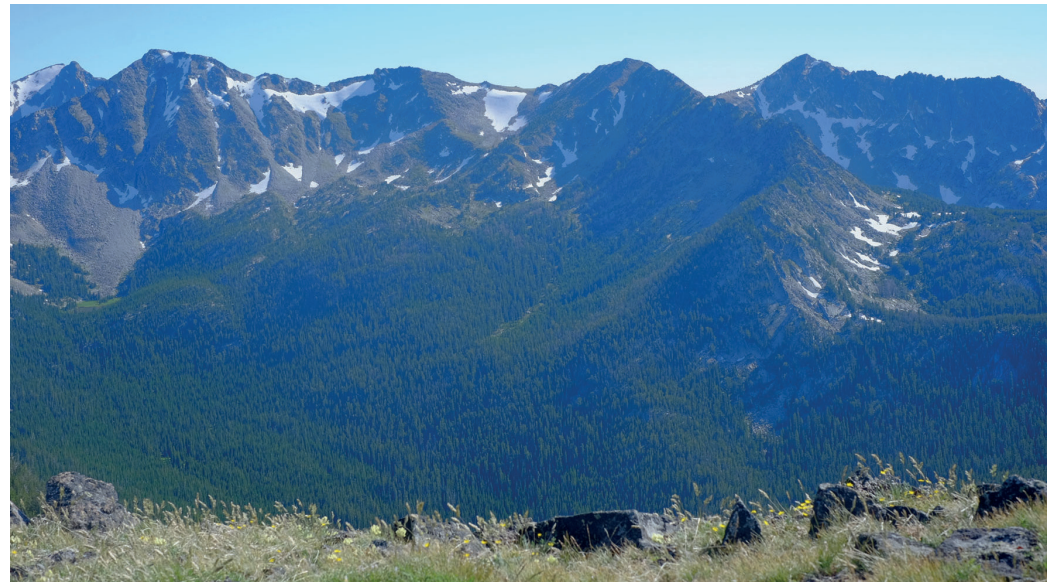

Figure 2 - The Pioneer Mountains looking south, 18 July 2020.

right and falls away steeply to the hiker's left. There is room to pass people approaching from the opposite direction, but not enough room to attain the recommended two meters for proper social distancing. There is really no good way around this lack of distance. One way is to wear masks and avert faces from approaching people and another is to wait at Storm Pass or at Goat Flat until the trail is clear. It is no hardship to wait at Storm Pass or at Goat Flat because it allows time to take in the view, drink water, and have a snack.

A steeply angled snowfield on the glacial cirque blocks the trail (or at least impedes progress) until late summer, and the field season only lasts for approximately two months before the next season's snows arrive. It is in part because of the short field season at Goat Flat that we are developing a means of remotely accessing our sensor data, which involves laboratory work and field testing of sensors and sensor networks. This project is funded by the Earth Science Information Partnership (ESIP) Lab Program and began in March 2020, but the timetable was revised so that preliminary lab and fieldwork took place in the summer 2020, with student researchers participating during the 2020 / 2021 academic year and summer field season of 2021. One student currently works on this in an essentially solitary mode in the Fabrication Lab of Electrical Engineering at MTU. We hold in-person meetings but wear masks and stay two metres apart. Sensor design is almost ideally suited for solitary work alternating with periods of interactive feedback.

Although the Anaconda-Pintler Wilderness is in Montana, which is generally uncrowded, the trail to Goat Flat is popular in the summertime and it is a connector trail for hikers on the Continental Divide Trail from Mexico to Canada. Once on the alpine tundra at Goat Flat, there are usually other hikers present, but it is a large enough place for easy social distancing, even when curious hikers quizzically approach our group as we survey plants and install soil temperature sensors.

25 July brought the first Goat Flat trip of the season for James Gallagher and I, Jamison Ehlers (sum- mer undergraduate research fellow/Electrical Engineering), Kevin Negus (collaborator in Electrical Engineering), Eva Negus (wife of Kevin) and their three border collies (Jess, Liz, and Meg). This five-person group was the largest of the summer. We limited group size to simplify logistics, avoid trampling the alpine plants, and reduce the likelihood of contracting COVID-19. Wearing masks on the $80 \mathrm{~km}$ drive to the research site cut down on coffee drinking and talking, so we had either a welcome silence or a lack of fun conversation, depending on your point of view. We began our hike on this cool Saturday by talking about things seen along the way (the beautiful lake, thistles, border collies, and snow), and a cheerful camaraderie ensued as we ascended the switchbacks to the Anaconda-Pintler Wilderness Boundary and up to Storm Pass. Along the trail from Storm Pass to Goat Flat, hikers approached from the other direction, so I sat down on a rocky ledge to obtain a safe distance. One hiker seemed not to realize why I was doing so, since he commented that it was nice to have a handy bench! Onward. We reached Goat Flat, and after lunch, we ventured down to the polygonal-patterned ground to take FLIR thermographic images of periglacial patterned ground and Krummholz trees, and to collect data on plant distribution. We practised social distancing and discussed ideas for remote sensing of snow data and ways to install sensor and LoWaRan (Long Range Wide Area Network) prototypes in the clayrich, compacted soil of the patterned ground. Here it felt like a research trip from any era, except that the conversation inevitably veered towards the coronavirus pandemic, the upward spike of cases in Montana, and the plans to open the campus for in-person classes on 17 August 2020.

A hiker approached our group and I did a double take when I realized that it was one of my former students, who is also a friend of my son's. He was hiking with his dog, Macy, and after a round of introductions he conveyed that he works for Senator Jon Tester, a valuable proponent of human rights, education, and the environment. Well done, I said, and congratulated him on his field of employment. Only in Montana, I thought, would I be in the wilderness, meet up with a former student, and talk about politics during a pandemic. We finished gathering our samples and walked uphill to the late-summer snowfield. There we took more FLIR images, marvelled at the snow algae and the view, and began our return journey. On the way, we saw other groups of hikers, none of whom seemed particularly interested in social distancing. A little disturbing, but we were outside and had no contact with them.

Friday, 30 July brought the second trip to Goat Flat. Our crew consisted of Kurtiss Winscot, (undergraduate student/Biological Sciences), Jennifer Krueger (Physician's Assistant), her dog Gus, and me. In case you get the idea that Montanans like to hike with their dogs, you are correct! The upward hike was laborious 
on this hot day, although still enchanting. We saw a hummingbird but very few other people, as the weekend crowds were not there. Upon reaching Goat Flat, we went to the snowfield where I shoe-skied down the slope, Gus basked in the snow, and we then walked down to the patterned ground to talk about Krummholz trees and collect botanical data and soil samples. It was a relief to be at Goat Flat on an uncrowded day. By uncrowded I mean that we saw approximately eight other people the whole day, in comparison to the previous trip, when we saw approximately thirty other people. The ride home, after hiking in the hot sun, seemed strenuous as we had to stop the vehicle, establish safe distances and then remove masks before drinking water. Still, mask-wearing is far, far better than contracting COVID-19!

James Gallagher and I returned to Goat Flat on 6 September to test devices and to collect botanical data. Since it was September, the crowds had diminished and there was far less worry about coming too close to other hikers. We saw maybe five other people during our eight or so hours in the field. It probably helped that our field day was sandwiched between a very hot smoky day during which smoke arrived from fires on the west coast of North America and the next day, which brought the first snow day of the season.

\section{Pioneer Mountains}

The field season at the high mountain sites finally began in July when enough snow had melted off. The first field research day was at the highest of the four SW Montana Global Research Observational Initiative in Alpine Environments (GLORIA) Target Region summits in the Pioneer Mountains. GLORIA is a network of long-term sites on the world's mountains for monitoring alpine plants in the context of climate change (Lamprecht et al. 2018). Mt. Keokirk $\left(2987 \mathrm{~m}, 45.5938^{\circ} \mathrm{N}, 112.9510^{\circ} \mathrm{W}\right)$ is reached by travelling along a gravel road until it gets so rocky that it is just as easy, and safer, to walk the rest of the way to the summit. James Gallagher, my husband, and a collaborator on remote data networks and sensors, and I set out in the morning and made only one stop, which was at the Salmon Fly Fishing Access Site along the Big Hole River (a famous trout stream). We continued to the site and saw one man coming the other way in a pickup truck, and two people and a dog in an ATV $4 \mathrm{X}$ 4 vehicle. We saw no one else at the site and were able to test our remote data access devices and survey the plants without having to worry about the virus. We did not see anyone else until we were almost back to the maintained part of the road, where we saw a bicyclist and two other trucks with people.

On 2 August, James Gallagher and I went to the treeline summit on Mt. Fleecer $\left(2873 \mathrm{~m}, 45.8264^{\circ} \mathrm{N}\right.$, $\left.112.8019^{\circ} \mathrm{W}\right)$, home of the lower three summits of the SW Montana GLORIA site. On this hot Sunday we concentrated on hydration and shading. We brought a sampling grid, the FLIR camera, and a prototypical

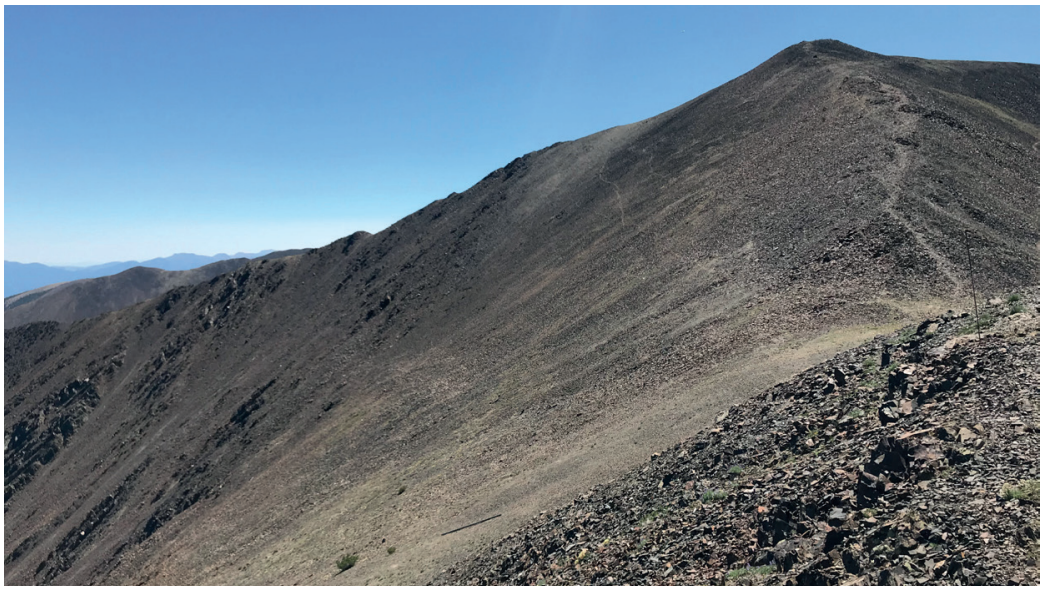

Figure 3 - The alpine scree of Red Mountain in the Highland Mountains of Montana, 4 August 2020.

test device for sending soil moisture data remotely. It worked! We saw no one else and only a few other vehicles on the road. The pandemic was not in evidence.

\section{Highland Mountains}

On Tuesday, 4 August Kurtiss Winscot and I ventured to Red Mountain (3070 m, $45.4554^{\circ} \mathrm{N}$, $112.2856^{\circ} \mathrm{W}$ ) to collect FLIR images of Krummholz whitebark pine (Pinus albicaulis) and spruce (Picea glauca) near the treeline, at approximately $2835 \mathrm{~m}$. We walked upwards along a road on alpine scree to a forest fire lookout building at $2926 \mathrm{~m}$., where two hikers (seemingly brothers) ascended the steps. I quickly put on my mask. The unmasked brothers arrived, but there was enough room for distance. For the one-mile hike to the site, we still saw twenty people, which by Montana standards was fairly crowded. Some radio tower maintenance guys drove down the service road, where the steep drop-offs and shingled surface provide little margin for error!

\section{Glacier National Park}

Glacier National Park (GNP) has partially reopened in June. Although Montana trails have mostly stayed open, some eastern GNP trails did not open in 2020 because the Blackfeet Nation closed its western border with GNP to prevent an influx of COVID-19 (Scott 2020). In September I hiked through the 2017 Sprague forest fire burn to the Sperry Chalet with Jennifer Krueger and Sharon Holsapple. Sperry Chalet's exterior stone walls survived the fire, but the interior had to be rebuilt. Social distancing was in place for overnight guests, but the access trail was congested. We hiked beyond the chalet to Comeau Pass via steep stone steps and emerged at what was once the Sperry Glacier's edge but is now a landscape of rocks, puddles, snowfields and one lobe of the remaining glacier. The Crown of the Continent Research Learning Center at GNP granted approval to set and photograph sampling frames, in which moss was close to the steep snowfield's edge, and monocots and then dicots ap- 
peared with distance. A mountain goat (Oreamnos americanus) arrived at our site and it crossed my mind that that they are probably instrumental in dispersing seeds and establishing plants on terrain exposed by glacial retreat. We found an old can that looked to be a remnant of a picnic at the glacier's former edge.

\section{Summary}

In summary, and speaking just for our particular group, alpine field research for the summer of 2020 was minimally impacted by the pandemic, although we all felt and talked about the sadness of the pandemic. The impact on our project's field season was minimal thanks to our effective isolation at relatively remote mountain sites in Montana. All researchers and associates who went on the field research trips live in the area, so no extensive travel was necessary, and we reached our field sites via driving and hiking. Even so, we limited group size, planned our travel to the sites carefully, and maintained strict social distancing, maskwearing, and hand-sanitizing protocols, following the recommendations of the Centers for Disease Control (2020). These recommendations are reflected in the Montana University System's requirements for maskwearing, social distancing, hand sanitization, cleaning, contact tracing and quarantining (Montana University System 2020) as well as the Montana Governor's mandate for mask-wearing (Bullock 2020), and the Montana Department of Health and Human Services guidelines (2020). We travelled directly to the sites and back to reduce the likelihood of contracting or spreading COVID-19. Travel to GNP was somewhat uncertain at the beginning of the pandemic, so 2020 brought a shift away from the patterned-ground alpine field sites at the national park and towards the more localized patterned-ground sites for field research and expeditions. Still, the pandemic has had an impact on alpine field research in that the relevant conferences are (for now) virtual, and time will tell what effect this has on the collaborative spirit of generating scientific ideas and research.

\section{Acknowledgements}

With appreciation for the contributions of Jocelyn Dodge, James Gallagher, Sharon Holsapple, Jennifer Krueger, Eva and Kevin Negus, Kurtiss Winscot, the Crown of The Continent Research Learning Center, the ESIP Lab Program, and Montana Technological University.

\section{References}

Apple, M.E., M.K. Ricketts \& A.C. Martin 2019. Plant functional traits and microbes vary with position on striped periglacial patterned ground at Glacier $\mathrm{Na}$ tional Park, Montana. Journal of Geographical Sciences 29: 1127-1141. Doi: 10.1007/s11442-019-1649-3
Brody, H., M.R. Rip, P. Vinten-Johansen, N. Paneth \& S. Rachman 2000. Map-making and myth-making in Broad Street: The London cholera epidemic, 1854. The Lancet 356(9223): 64-68. Doi: 10.1016/S01406736(00)02442-9

Bullock, S. 2020. Directive implementing Executive Orders 2-2020 and 3-2020 and providing for the mandatory use of face coverings in certain settings. Available at: https://dphhs.mt.gov/Portals/85/ Documents/NewsLetters/MaskDirective.pdf

Center for Disease Control 2020. How to Protect Yourself and Others. Updated September 11, 2020. Available at: https:/ /www.cdc.gov/coronavirus/2019ncov/prevent-getting-sick/prevention.html.

Chen, N., M. Zhou, X. Dong, J. Qu, F. Gong, Y. Han, et al. 2020. Epidemiological and clinical characteristics of 99 cases of 2019 novel coronavirus pneumonia in Wuhan, China: a descriptive study. The Lancet 395(10223): 507-513. Doi: 10.1016/S01406736(20)30211-7

Dong, E., H. Du \& L. Gardner 2020. An interactive web-based dashboard to track COVID-19 in real time. The Lancet Infectious Diseases 20(5): 533-534. Doi: 10.1016/S1473-3099(20)30120-1.

Lamprecht, A., P.R. Semenchuk, K. Steinbauer, M. Winkler \& H. Pauli 2018. Climate change leads to accelerated transformation of high-elevation vegetation in the central Alps. New Phytologist 220: 447-459. Doi: 10.1111/nph.15290.

Montana Department of Health and Human Services 2020. Coronavirus Disease 2019 (COVID-19). Available at: https://dphhs.mt.gov/publichealth/ cdepi/diseases/coronavirusmt

Montana Department of Health and Human Services and Montana State Library 2020. MONTANA RESPONSE: COVID-19 - Coronavirus - Global, National, and State Information Resources. Available at: https://montana.maps.arcgis.com/apps/MapSeries/ index.html?appid=7c34f3412536439491 $\mathrm{adcc} 2103421$ $\mathrm{d} 4 \mathrm{~b}$

Montana University System. MUS Healthy Fall 2020. Planning Guidelines for Campuses. Available at: https://www.mus.edu/coronavirus/healthy-fall2020-planning.html\#bs

Scott, T.2020. Blackfeet Tribe Closes Eastern Border to Glacier Park. The Flathead Beacon. Available at: https:/ / flatheadbeacon.com/2020/06/25/blackfeettribe-closes-eastern-border-glacier-park/

\section{Author}

Martha E. Apple

Department of Biological Sciences, Montana Technological University, Butte, Montana, USA. E-mail: mapple@mtech.edu

(C) all photographs: Martha E. Apple 